International Journal of Medical Anesthesiology 2021; 4(1): 127-130

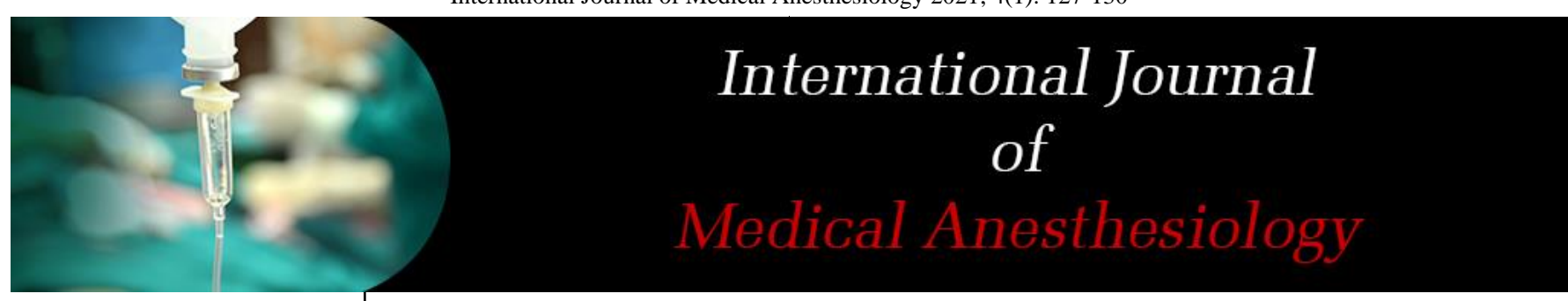

E-ISSN: 2664-3774

P-ISSN: 2664-3766

www.anesthesiologypaper.com

IJMA 2021; 4(1): 127-130

Received: 16-11-2020

Accepted: 19-12-2020

Dr. Shankar Kantharaju

Assistant Professor,

Department of Anesthesia,

Raja Rajeshwari Medical

College \& Hospital, Bangalore,

Karnataka, India

Dr. Lokesh SB

Senior Resident, Department of Anesthesia, ESIC Medical

College \& PGIMSR and Model

Hospital, Bangalore,

Karnataka, India

Dr. Gayatri Chidanand Kadaganchikar

Consultant, Jindal Sanjeevani Multispeciality Hospital,

Torangallu, Bellary,

Karnataka, India
Corresponding Author: Dr. Lokesh SB

Senior Resident, Department of Anesthesia, ESIC Medical College \& PGIMSR and Model

Hospital, Bangalore,

Karnataka, India

\section{Comparison of haemodynamic changes during propofol induction by fentanyl and butorphanol as pre-medication agent}

\author{
Dr. Shankar Kantharaju, Dr. Lokesh SB and Dr. Gayatri Chidanand \\ Kadaganchikar
}

DOI: $\underline{\text { https://doi.org/10.33545/26643766.2021.v4.i1b.260 }}$

\begin{abstract}
Propofol decreases systemic blood pressure. This is accompanied by corresponding changes in cardiac output and systemic vascular resistance. Systemic blood pressure reductions of $50 \%$ have been seen with $2 \mathrm{mg} / \mathrm{kg}$ bolus of propofol. A negative inotropic effect of propofol may be due to decrease in intracellular calcium availability secondary to inhibition of transsarcolemmal calcium influx. Base line heart rate, blood pressure, $\mathrm{SpO}_{2}$, Respiratory rate and Entropy values was recorded. Patients were randomly allocated into two groups of 70 each using sealed envelope technique. In our study we have found that suppression of intubation response was better with fentanyl $2 \mathrm{mcg} / \mathrm{kg}$ than butorphanol $20 \mathrm{mcg} / \mathrm{kg}$ which is statistically significant.
\end{abstract}

Keywords: butorphanol, pre-medication agent, haemodynamic changes

\section{Introduction}

Propofol is one of a group of alkylphenols. The alkylphenols are oils at room temperature and insoluble in aqueous solution, but they are highly lipid soluble. It has pH of 7 and pKa of 11 , appears as a slightly viscous, white milky substance. It is stable at room temperature and is not light sensitive. If a dilute solution of propofol is required, it is compatible with $5 \%$ dextrose in water ${ }^{[1]}$

Propofol is presumed to exert its sedative hypnotic effects through interaction with GABA, the principal inhibitory neurotransmitter in the CNS. When the GABA receptor is activated, transmembrane chloride conductance increases, resulting in hyperpolarization of post synaptic cell membrane and functional inhibition of post synaptic neuron. Propofol interacts with specific components of GABA receptor complex, appears to decrease the rate of dissociation of GABA from its receptor. This increases the duration of GABA activated opening of the chloride channel with resulting hyperpolarization of cell membrane ${ }^{[2]}$.

Propofol decreases systemic blood pressure. This is accompanied by corresponding changes in cardiac output and systemic vascular resistance. Systemic blood pressure reductions of $50 \%$ have been seen with $2 \mathrm{mg} / \mathrm{kg}$ bolus of propofol. A negative inotropic effect of propofol may be due to decrease in intracellular calcium availability secondary to inhibition of transsarcolemmal calcium influx. The relaxation of vascular smooth muscle produced by propofol is primarily due to inhibition of sympathetic vasoconstrictor nerve activity. Stimulation produced by direct laryngoscopy \& intubation of the trachea reverses blood pressure effect of propofol. This drug is more effective than thiopentone in blunting the magnitude of this pressor response. Propofol also effectively blunts the hypertensive response to placement of laryngeal mask airway.

Fentanyl is a highly selective $\mu$ receptor agonist, which is mainly responsible for its analgesic properties. It acts by increasing intra-cellular calcium concentration which in turn increases $\mathrm{K}+$ conductance and hyperpolarization of cell membranes. This decreased membrane conductance decreases pre and post synaptic responses. Analgesia is produced principally through interaction with $\mu$ receptor at supra spinal sites. It also binds to k receptor causing spinal analgesia, sedation, and anaesthesia ${ }^{[3,4]}$.

Butorphanol tartrate is a synthetic opioid partial agonist analgesic. Butorphanol is an agonistantagonist opioid that resembles pentazocine. Compared with pentazocine, its agonist effects 
are about 20 times greater, whereas its antagonist actions are 10 to 30 times greater ${ }^{[5]}$.

Heart rate and blood pressure were not significantly altered after butorphanol i.v. in normal volunteers although some studies do indicate some indices of cardiovascular function can be altered. A dose of $25 \mathrm{mcg} / \mathrm{kg}$ butorphanol, i.v., increased pulmonary artery pressure, pulmonary wedge pressure, left ventricular end-diastolic pressure, systemic arterial pressure, pulmonary vascular resistance, and cardiac index. As a nasal preparation, hypotension did not occur with any appreciable frequency. No change in cardiac or vital signs were observed in volunteers receiving multiple doses of 1-4 mg for 16 days. Interestingly, butorphanol (1.5$6 \mathrm{mg} / 70 \mathrm{~kg}$, i.m.) dampened the tachycardic response to cocaine administration ${ }^{[6]}$.

\section{Methodology}

Design of Study

Prospective Randomized control trial

\section{Sample Size}

To detect a minimum of $20 \%$ difference in propofol consumption between fentanyl and butorphanol a minimum of 67 patients was required when alpha error is kept at 0.05 and power of study at $80 \%$

So sample size was 70 patients in each group.

\section{Inclusion Criteria}

- 18-65 years of age of either sex

- ASA physical status I and II for surgeries under general anaesthesia

- Patients who gave informed written consent

\section{Exclusion Criteria}

- Patient refusing to participate in the study.

- Patients with history of Neurological, Respiratory,

- Cardiovascular and Hepatic disorder.

- BMI more than 30 and individuals with difficult airway.

- Allergy to the study drug.

- Patients on opioids, sedatives, anti-psychotics, antiepileptics.

- Pregnant or lactating mothers.

- Alcoholic

Base line heart rate, blood pressure, $\mathrm{SpO}_{2}$, Respiratory rate and Entropy values was recorded.

Patients were randomly allocated into two groups of 70 each using sealed envelope technique.

Premedicated with Inj. Glycopyrrolate $0.2 \mathrm{mg}$ plus

Group F: Inj.Fentanyl 2mcg/ kg

Group B: Inj.Butorphanol 20mcg/ kg

\section{Results}

Table 1: Comparison of Heart rate (bpm) in two groups of patients studied

\begin{tabular}{|c|c|c|c|c|}
\hline Heart rate $(\mathrm{bpm})$ & Group F & Group B & Total & P value \\
\hline Baseline & $86.86 \pm 6.24$ & $85.80 \pm 6.91$ & $86.32 \pm 6.58$ & 0.344 \\
\hline 1 Minute after Premedication & $86.94 \pm 6.16$ & $84.56 \pm 7.50$ & $85.75 \pm 6.94$ & $0.042 *$ \\
\hline 5 Minute after premedication & $82.71 \pm 5.76$ & $83.16 \pm 5.92$ & $82.94 \pm 5.82$ & 0.654 \\
\hline At Induction & $83.20 \pm 5.43$ & $82.56 \pm 6.01$ & $82.88 \pm 5.72$ & 0.508 \\
\hline 1 Minute after induction & $82.06 \pm 5.80$ & $81.80 \pm 6.72$ & $81.93 \pm 6.25$ & 0.809 \\
\hline 2 Minute after induction & $80.59 \pm 7.43$ & $80.71 \pm 6.80$ & $80.65 \pm 7.10$ & 0.915 \\
\hline 1 Minute after intubation & $90.51 \pm 9.33$ & $93.20 \pm 7.21$ & $91.86 \pm 8.42$ & $0.059+$ \\
\hline 2 Minute after intubation & $87.97 \pm 7.28$ & $88.91 \pm 6.02$ & $88.44 \pm 6.68$ & 0.405 \\
\hline 3 Minute after intubation & $85.16 \pm 6.58$ & $86.51 \pm 6.10$ & $85.84 \pm 6.36$ & 0.208 \\
\hline 4 Minute after intubation & $82.59 \pm 6.25$ & $85.47 \pm 6.27$ & $84.03 \pm 6.40$ & $0.007 * *$ \\
\hline 5 Minute after intubation & $81.49 \pm 6.11$ & $84.27 \pm 6.11$ & $82.88 \pm 6.25$ & $0.008 * *$ \\
\hline
\end{tabular}

- Heart rate was found to be within normal limits in both the groups.

- Significant difference in heart rate is observed 1 minute after pre-medication where heart rate is slightly less in
Group B compared to Group F

- Significant difference in heart rate @ 4 \& 5 minutes after intubation is observed where heart rate is slightly high in Group B than Group F

Table 2: Comparison of SBP (mm Hg) in two groups of patients studied

\begin{tabular}{|c|c|c|c|c|}
\hline SBP $(\mathbf{m m}$ Hg) & Group F & Group B & Total & P value \\
\hline Baseline & $128.13 \pm 8.65$ & $127.91 \pm 8.46$ & $128.02 \pm 8.52$ & 0.882 \\
\hline 1 Minute after Premedication & $128.07 \pm 8.49$ & $127.20 \pm 8.23$ & $127.64 \pm 8.34$ & 0.539 \\
\hline 5 Minute after premedication & $124.50 \pm 8.16$ & $124.57 \pm 7.81$ & $124.54 \pm 7.96$ & 0.958 \\
\hline At Induction & $124.03 \pm 7.73$ & $124.76 \pm 7.34$ & $124.39 \pm 7.52$ & 0.568 \\
\hline 1 Minute after induction & $117.23 \pm 6.52$ & $115.63 \pm 7.74$ & $116.43 \pm 7.17$ & 0.188 \\
\hline 2 Minute after induction & $106.26 \pm 8.17$ & $107.81 \pm 8.63$ & $107.04 \pm 8.41$ & 0.275 \\
\hline 1 Minute after intubation & $130.04 \pm 8.45$ & $129.47 \pm 9.34$ & $129.76 \pm 8.88$ & 0.705 \\
\hline 2 Minute after intubation & $127.20 \pm 7.63$ & $131.07 \pm 8.00$ & $129.14 \pm 8.03$ & $0.004^{* *}$ \\
\hline 3 Minute after intubation & $125.17 \pm 8.07$ & $128.76 \pm 8.42$ & $126.96 \pm 8.42$ & $0.011^{*}$ \\
\hline 4 Minute after intubation & $121.86 \pm 7.30$ & $126.69 \pm 8.41$ & $124.27 \pm 8.21$ & $<0.001^{* *}$ \\
\hline 5 Minute after intubation & $117.36 \pm 8.96$ & $123.00 \pm 8.49$ & $120.18 \pm 9.14$ & $<0.001^{* *}$ \\
\hline
\end{tabular}


Statistically significant increase in SBP is seen in Group B

minutes compared to Group F especially @ post-intubation 2,3,4,5

Table 3: Comparison of DBP ( $\mathrm{mm} \mathrm{Hg}$ ) in two groups of patients studied

\begin{tabular}{|c|c|c|c|c|}
\hline DBP $(\mathbf{m m}$ Hg) & Group F & Group B & Total & P value \\
\hline Baseline & $81.30 \pm 6.36$ & $80.99 \pm 6.38$ & $81.14 \pm 6.35$ & 0.771 \\
\hline 1 Minute after Premedication & $81.14 \pm 6.33$ & $81.03 \pm 6.17$ & $81.09 \pm 6.23$ & 0.914 \\
\hline 5 Minute after premedication & $78.47 \pm 5.90$ & $78.77 \pm 6.10$ & $78.62 \pm 5.98$ & 0.768 \\
\hline At Induction & $79.09 \pm 6.53$ & $78.94 \pm 6.41$ & $79.01 \pm 6.45$ & 0.896 \\
\hline 1 Minute after induction & $74.41 \pm 5.49$ & $73.53 \pm 6.91$ & $73.97 \pm 6.24$ & 0.403 \\
\hline 2 Minute after induction & $69.29 \pm 8.08$ & $68.46 \pm 8.21$ & $68.87 \pm 8.13$ & 0.548 \\
\hline 1 Minute after intubation & $84.40 \pm 6.91$ & $83.54 \pm 6.71$ & $83.97 \pm 6.80$ & 0.458 \\
\hline 2 Minute after intubation & $80.36 \pm 6.73$ & $85.00 \pm 6.1$ & $82.68 \pm 6.81$ & $<0.001^{* *}$ \\
\hline 3 Minute after intubation & $79.76 \pm 7.40$ & $83.61 \pm 5.61$ & $81.69 \pm 6.82$ & $0.001^{* *}$ \\
\hline 4 Minute after intubation & $78.56 \pm 7.17$ & $82.51 \pm 5.35$ & $80.54 \pm 6.61$ & $<0.001^{* *}$ \\
\hline 5 Minute after intubation & $75.53 \pm 6.97$ & $81.27 \pm 6.00$ & $78.40 \pm 7.09$ & $<0.001^{* *}$ \\
\hline
\end{tabular}

Student $\mathrm{t}$ test

Statistically significant increase in DBP is seen in Group B minutes compared to Group F especially @ post-intubation 2,3,4,5

Table 4: Comparison of MAP ( $\mathrm{mm} \mathrm{Hg}$ ) in two groups of patients studied

\begin{tabular}{|c|c|c|c|c|}
\hline MAP $(\mathbf{m m}$ Hg) & Group F & Group B & Total & P value \\
\hline Baseline & $96.93 \pm 6.46$ & $96.64 \pm 6.48$ & $96.79 \pm 6.45$ & 0.794 \\
\hline 1 Minute after Premedication & $96.79 \pm 6.34$ & $96.41 \pm 6.22$ & $96.60 \pm 6.26$ & 0.727 \\
\hline 5 Minute after premedication & $93.79 \pm 5.84$ & $94.00 \pm 5.91$ & $93.89 \pm 5.85$ & 0.829 \\
\hline At Induction & $94.03 \pm 6.03$ & $94.21 \pm 5.97$ & $94.12 \pm 5.98$ & 0.855 \\
\hline 1 Minute after induction & $88.67 \pm 4.85$ & $87.56 \pm 6.70$ & $88.11 \pm 5.86$ & 0.262 \\
\hline 2 Minute after induction & $81.61 \pm 7.72$ & $81.53 \pm 8.17$ & $81.57 \pm 7.92$ & 0.949 \\
\hline 1 Minute after intubation & $99.49 \pm 6.52$ & $98.89 \pm 6.70$ & $99.19 \pm 6.60$ & 0.592 \\
\hline 2 Minute after intubation & $95.99 \pm 6.34$ & $100.37 \pm 5.94$ & $98.18 \pm 6.51$ & $<0.001^{* *}$ \\
\hline 3 Minute after intubation & $94.89 \pm 6.88$ & $98.67 \pm 5.67$ & $96.78 \pm 6.56$ & $0.001^{* *}$ \\
\hline 4 Minute after intubation & $93.03 \pm 6.52$ & $97.24 \pm 5.50$ & $95.14 \pm 6.37$ & $<0.001^{* *}$ \\
\hline 5 Minute after intubation & $96.93 \pm 6.46$ & $96.64 \pm 6.48$ & $96.79 \pm 6.45$ & $<0.001^{* *}$ \\
\hline
\end{tabular}

Student $t$ test

Statistically significant increase in MAP is seen in Group B minutes compared to Group F especially @ post-intubation 2,3,4,5

Table 5: Comparison of $\mathrm{SpO} 2 \%$ in two groups of patients studied

\begin{tabular}{|c|c|c|c|c|}
\hline SpO2\% & Group F & Group B & Total & P value \\
\hline Baseline & $98.66 \pm 0.81$ & $98.69 \pm 0.79$ & $98.67 \pm 0.80$ & 0.833 \\
\hline 1 Minute after Premedication & $98.63 \pm 0.75$ & $98.66 \pm 0.68$ & $98.64 \pm 0.71$ & 0.813 \\
\hline 5 Minute after premedication & $95.94 \pm 0.88$ & $96.37 \pm 1.13$ & $96.16 \pm 1.03$ & 0.014 \\
\hline At Induction & $96.43 \pm 1.37$ & $96.84 \pm 1.49$ & $96.50 \pm 01.47$ & 0.005 \\
\hline 1 Minute after induction & $99.96 \pm 0.20$ & $99.97 \pm 0.17$ & $99.96 \pm 0.19$ & 0.652 \\
\hline 2 Minute after induction & $99.94 \pm 0.29$ & $99.93 \pm 0.31$ & $99.94 \pm 0.30$ & 0.779 \\
\hline 1 Minute after intubation & $99.97 \pm 0.17$ & $99.97 \pm 0.17$ & $99.97 \pm 0.17$ & 1.000 \\
\hline 2 Minute after intubation & $99.99 \pm 0.12$ & $99.99 \pm 0.12$ & $99.99 \pm 0.12$ & 1.000 \\
\hline 3 Minute after intubation & $99.96 \pm 0.27$ & $99.96 \pm 0.27$ & $99.96 \pm 0.26$ & 1.000 \\
\hline 4 Minute after intubation & $99.97 \pm 0.17$ & $99.97 \pm 0.17$ & $99.97 \pm 0.17$ & 1.000 \\
\hline 5 Minute after intubation & $99.99 \pm 0.12$ & $99.99 \pm 0.12$ & $99.99 \pm 0.12$ & 1.000 \\
\hline
\end{tabular}

Student $\mathrm{t}$ test

$\mathrm{SpO} 2$ is comparable between group $\mathrm{F}$ and Group B without significant difference

\section{Discussion}

Suppression of intubation response was better with fentanyl $2 \mathrm{mcg} / \mathrm{kg}$ group than butorphanol $20 \mathrm{mcg} / \mathrm{kg}$ group which shows statistically significant difference especially at 2,3,4,5 minutes post-intubation

Pandit SK et al. ${ }^{[7]}$ measured perioperative vital signs during laparoscopy using butorphanol $40 \mathrm{mcg} / \mathrm{kg}$ and fentanyl $2 \mathrm{mcg} / \mathrm{kg}$. They found that the patients who received butorphanol experienced lesser increases in heart rate and systolic blood pressure two minutes after intubation compared to fentanyl group.

In our study, patients who received butorphanol $20 \mathrm{mcg} / \mathrm{kg}$ had higher heart rate and blood pressure compared to fentanyl $2 \mathrm{mcg} / \mathrm{kg}$ group which could be possibly explained because of higher dose of butorphanol[40 $\mathrm{mcg} / \mathrm{kg}]$ used in Pandit SK et al. Study.

Philip BK et al. ${ }^{[8]}$ study measured vital signs in laparoscopic surgeries under general anaesthesia and demonstrated post intubation lower pulse rate $\&$ blood pressure in butorphanol 
$20 \mathrm{mcg} / \mathrm{kg}$ group than fentanyl $1 \mathrm{mcg} / \mathrm{kg}$ group.

In our study, patients who received butorphanol $20 \mathrm{mcg} / \mathrm{kg}$ had higher heart rate and blood pressure compared to fentanyl $2 \mathrm{mcg} / \mathrm{kg}$ group which could be possibly explained because of lower dose of fentanyl[1 $1 \mathrm{mcg} / \mathrm{kg}]$ used in Philip BK et al. Study.

Jasleen kaur et al. [9] study measured post-intubation response by using pre-medication with fentanyl $2 \mathrm{mcg} / \mathrm{kg}$, butorphanol $20 \mathrm{mcg} / \mathrm{kg}$ and $40 \mathrm{mcg} / \mathrm{kg}$ respectively. Study showed all the three groups had a comparable increase in HR in the post-intubation period, which returned to baseline within 5 minutes.

In our study we have found that suppression of intubation response was better with fentanyl $2 \mathrm{mcg} / \mathrm{kg}$ than butorphanol $20 \mathrm{mcg} / \mathrm{kg}$ which is statistically significant.

This is in contrast to the study of Jasleen kaur et al. Which demonstrated suppression of intubation response was comparable between butorphanol and fentanyl.

The major drawback of propofol is reduction in blood pressure with the standard induction dose of propofol. A typical induction dose of propofol $(2 \mathrm{mg} / \mathrm{kg})$ results in an approximate $30 \%$ reduction in SBP Reduction in the requirement of induction dose reduces the hemodynamic effects of propofol ${ }^{[10]}$.

Because of dose sparing effect of induction dose of propofol by opiods, haemodynamic effects of propofol is reduced.

The hemodynamic stability with butorphanol was comparable to fentanyl without any statistical significance.

Jasleen kaur et al. ${ }^{[9]}$ study demonstrated changes in vital parameters at induction with propofol using fentanyl $2 \mathrm{mcg} / \mathrm{kg}$, butorphanol $20 \mathrm{mcg} / \mathrm{kg}$ and $40 \mathrm{mcg} / \mathrm{kg}$ respectively. MAP at induction was $82.50 \pm 4.53$ in Group F, $85.80 \pm 9.04$ in Group B20 and 84.60 \pm 7.35 in Group B40 where the incidence of fall in blood pressure is $<30 \%$ in all three groups.

Our study is in consistent with the previous study of Jasleen kaur et al. Which demonstrated $<30 \%$ reduction in blood pressure in all three groups

\section{Conclusion}

We conclude that butorphanol $20 \mu \mathrm{g} / \mathrm{kg}$ reduces the induction requirement of propofol comparable to that of fentanyl $2 \mu \mathrm{g} / \mathrm{kg}$ and confers hemodynamic stability.

It is therefore an acceptable alternative opioid to fentanyl as an adjuvant to balanced general anesthesia.

\section{References}

1. Viertiö-Oja H, Maja V, Sarkela M, Talja P, Vakkuri A, Merilainen $\mathrm{P}$ et al. Description of the Entropy algorithm as applied in the Datex-Ohmeda S/5 Entropy Module. Acta Anaesthesiologica Scandinavica 2004;48(2):154-161.

2. Vakkuri A, Talja P, Mustola S, Sampson T, YliHankala A, Virtio-Oja $\mathrm{H}$ et al. Time-frequency balanced spectral entropy as a measure of anesthetic drug effect in central nervous system during sevoflurane, propofol, and thiopental anesthesia. Acta Anaesthesiologica Scandinavica 2004;48(2):145-153.

3. Klockars JG, Hiller A, Munte S, Van Gils MJ, Taivaninen T. Spectral entropy as a measure of hypnosis in children. Anesthesiology 2006;104:708-17.

4. Singh V, Pathak M, Singh GP. Oral midazolam and oral butorphanol premedication. Indian $\mathrm{J}$ Pediatr 2005;72:741-4.
5. Vogelsang J, Hayes SR. Butorphanol tartrate (stadol): A review. J Post Anesth Nurs 1991;6:129-35.

6. Sano T, Nishimura R, Mochizuki M, Sasaki N. Effects of midazolam-butorphanol, acepromazine-butorphanol and medetomidine on an induction dose of propofol and their compatibility in dogs. J Vet Med Sci 2003;65:1141-3.

7. Pandit SK, Kothary SP, Pandit UA, Mathai MK. Comparison of fentanyl and buturphanol for outpatient anesthesia. Can J Anesthesia 1987;34:130-4.

8. Philip BK, Scott DA, Freiberger D, Gibbs RR, Hunt C, Murray E. Butorphanol compared with fentanyl in general anaesthesia for ambulatory laparoscopy. Can J Anaesth 1991;38:183-6.

9. Kaur J, Srilata M, Padmaja D, Gopinath R, Bajwa SJ, Kenneth DJ et al. Dose sparing of induction dose of propofol and fentanyl: A comparison based on entropy analysis. Saudi J Anaesth 2013;7:128-33.

10. Robert SK. Opioid agonists and antagonists. Chapter 3. In: Pharmacology and physiology in anaesthesia practice. 3rd edition. Lipincott Raven publishers 1999, $77-112$. 